\title{
Covid-19 Sürecinde Fiziksel Aktivite Amacıyla Açık Rekreasyon Alanlarını Tercih Eden Bireylerin Mekân Seçimi ve Fiziksel Aktiviteye Katılımını Etkileyen Faktörler
}

\author{
Hasan Suat AKSU ${ }^{1}$
}

\author{
Alper KAYA ${ }^{2}$
}

Fatma ARSLAN ${ }^{3}$

\section{$\ddot{\mathbf{O} z}$}

Covid-19 sürecinde açık alanların ön plana çıkması ve bu alanların seçim kriterleri göz önüne alındığında fiziksel aktivite amaçlı rekreasyon alanların kullanımını incelemek bir gereklilik olarak ortaya çıkmaktadır. Çalışmanın çıkış noktası, özellikle covid 19 sürecinde artan fiziksel aktivite için açık alan rekreasyon alanlarının kullanımının demografik veriler ışığında araştırılmasıdır. Bu sebeple araştırmanın amacı, covid-19 sürecinde fiziksel aktivite amaçlı rekreasyon alanlarını tercih eden kullanıcıların mekan seçimlerinde etkili olan faktörleri tespit edebilmektir. Betimsel tarama deseni kullanılarak tasarlanan bu çalışmada olasılıksız örnekleme yöntemlerinden kolayda örneklem seçilmiştir. Araştırmanın evrenini Konya ilinde ikamet eden 1865 yaş arası rekreasyon alanlarını kullanan yetişkinler oluştururken, örneklem grubu 450 kişidir. Çalışmanın verileri "Fiziksel Aktivite Mekânı Değerlendirme" ölçeği kullanılarak elde edilmiştir. Ölçek, fiziksel aktivite amaçlı mekan seçimi ve mekan seçimi kısıtlayıcıları olarak iki alt boyuta sahiptir. Verilerin analiz kısmında bağımsız örneklemler için t-testi ve ANOVA testleri kullanılmıștır. Elde edilen bulgulara göre, mekan seçimi alt boyutunun erkeklere kıyasla kadınlarda, kısıtlayıcılar alt boyutunun ise kadınlara kıyasla erkeklerde anlamlı bir şekilde farklılaştığı tespit edilmiştir. Sonuç olarak, fiziksel aktivite amaçlı rekreasyon alanlarının tercihinde alanın temizliği, ışıklandırma ve alanın bakımlı olmasının, alan tercihinde etkili faktörlerin temizlik ve güvenlik unsurunda birleştiğini göstermektedir. Bir diğer sonuç ise, mekan seçiminde, alanın yeterince ağaçlı olmamasının en etkin kısıtlayıcı olduğu tespit edilmiştir.

Anahtar Kelimeler: Rekreasyon alanları, Covid-19, Fiziksel aktivite katılımı, Mekan seçimi

\section{Factors Affecting the Selection of Space and Participation in Physical Activity of Individuals Preferring Outdoor Recreation Areas for Physical Activity in the Covid-19 Process}

\begin{abstract}
Considering the prominence of open spaces in the Covid-19 process and the selection criteria of these areas, it is a necessity to examine the use of recreation areas for physical activity. The starting point of the study is to investigate the use of outdoor recreation areas for increased physical activity, especially in the covid 19 process, in the light of demographic data. For this reason, the aim of the research is to determine the factors that affect the venue choices of users who prefer physical activity recreation areas during the covid-19 process. In this study, which was designed using a descriptive scanning design, convenience sampling was chosen from the non-probability sampling methods. The population of the research consists of adults between the ages of

\footnotetext{
${ }^{1}$ Sorumlu Yazar; Selçuk Üniversitesi, Konya-Türkiye, gazihasansuat@gmail.com https://orcid.org/0000-00018196-129X

2 Necmettin Erbakan Üniversitesi, Konya-Türkiye, alper.kaya.gazi@gmail.com https://orcid.org/0000-0002-

${ }^{3}$ Necmettin Erbakan Üniversitesi, Konya-Türkiye, fatmarslan@erbakan.edu.tr https://orcid.org/0000-0003$\underline{2025-8765}$
} 0364-4122
\end{abstract}


18-65 residing in Konya and using recreational areas, while the sample group is 450 people. The data of the study were obtained by using the "Physical Activity Space Evaluation" scale. The scale has two subdimensions as constraints of venue selection for physical activity and site selection constraints. In the analysis part of the data, t-test and ANOVA tests were used for independent samples. According to the findings, it was determined that the sub-dimension of space selection differed significantly in women compared to men, and the sub-dimension on constraints differed significantly in men compared to women. As a result, it shows that the cleanliness of the area, the lighting and the well-keptness of the area in the preference of recreation areas for physical activity, the factors that affect the area preference are combined with the elements of cleanliness and security. Another result is that it has been determined that the lack of trees in the area is the most effective constraint in the selection of the place.

Keywords: Recreation areas, Covid-19, Physical activity participation, Venue selection

\section{GíRiş}

Son y1llarda fiziksel aktivite, koruyucu sağl1k hizmetlerinin bir parçası olarak görülmekte olup, etkileri üzerine her geçen gün artan çalışmalara konu olmaktadır (Erdemir, 2020; Paravidino ve et al., 2020; Shimada et al., 2019; Caspersen ve Powell, 1985). Fiziksel aktivite, sadece sportif faaliyetler ya da planlı aktiviteler ile sınırlı olmayan, yürüyüş-bisiklet binme-dans-bahçe işleri gibi aktiviteleri kapsayan kas ve eklemlerin kullanımı ile farkl1 yoğunluklarda gerçekleştirilen aktiviteler olmakla beraber (Iş̧kgöz, Esentaş ve Şahin, 2018), birey üzerinde zihinsel ve duygusal yönden birçok olumlu etkiye sahiptir.

Mevcut araştırmalarda düzenli fiziksel aktivitenin kardiyovasküler hastalıklar, kalp ve dolaşım sistemini, solunum sistemi ve metabolizma gibi sistemleri güçlendirdiği ve bununla birlikte dopamin (mutluluk) hormonunun salgılanmasina da neden olduğu bahsedilmektedir (Brown et al., 2014; Cairney, Dudley, Kwan, Bulten ve Kriellaars 2019; Caspersen ve Powell, 1985; Nieman ve Wentz, 2019; Tan, Alén, Wiklund, Partinen, Cheng, 2016; Çuhadar vd., 2019; Vancampfort ve Ward, 2019; Taskin et al., 2018; Pekel vd., 2020; Uzun vd., 2020; Kavlak vd., 2021). Morris et al. (1953) yapmış oldukları çalışmada, fiziksel aktivite ve kardiyovasküler hastalıklar arasında ilişkiyi incelemişler ve pozitif bir iliş̧ki olduğunu belirtmişlerdir. Ayrıca, Londra'da çift katlı otobüs şoförleri üzerine yapılan öncü araştırmalarından elde ettikleri sonuçlara göre; fiziksel olarak aktif şoförlerin kardiyovasküler hastalık oranları, sedanter otobüs şoförlerine kıyasla çok daha düşük olduğu saptamakla birlikte (Morris et al.,
1953), o zamandan bugüne sedanter yaşamın kardiyovasküler hastalık için yerleşik bir risk faktörü olduğunu bildirmişlerdir. Grande et al. (2015) 1990-2014 y1llar1 arasinda solunum sistemi üzerine fiziksel aktivitelerin etkisini araştıran 11 çalışmayı incelemiş ve birincil sonuç olarak hastalık epizodu başına semptom sayıs1, egzersiz yapan katılımcilarda 1.1 ila 1.7. gün olarak azaldığ tespit etmişlerdir.

Dolayısıyla fiziksel aktivitelerin solunum sistemi üzerine pozitif etkilerini birçok çalışma destekler niteliktedir (Elnaggar, 2021; Nambi et al., 2021; Scudiero et al., 2021; Zhang et al., 2021). Fiziksel aktivitenin bu faydaları göz önünde bulundurulduğunda Covid-19 üzerindeki etkileri de birçok araştırmacı tarafından incelenmeye başlanmıştır (Burtscher, Burtscher ve Millet, 2020; Crisafulli ve Pagliaro, 2020; Faulkner et al., 2020; Peçanha, Goessler, Roschel ve Gualano, 2020; Shahidi, Stewart Williams ve Hassani, 2020; Woods et al., 2020; Bayram ve Kavlak, 2021).

Fiziksel aktivite sağlıklı bir yaşamın anahtarı olarak belirtilmektedir (Crisafulli ve Pagliaro, 2020; Peçanha et al., 2020; Kavlak, 2020). Fakat fiziksel aktiviteye katılım her durumda mümkün olmamakla birlikte bu katılımı etkileyen birtakım hususlar bulunmaktadır. $\mathrm{Bu}$ hususlar bireyin rekreasyon faaliyetlerinden (Varol, Köseoğlu ve Kuzu, 2019) biri olan fiziksel aktiviteye katılım arzusunu körelten, rekreasyon faaliyetlerinin avantajlarını yok eden ve bu faaliyetlerden alınması planlanan haz-mutluluk ya da memnuniyet derecesini azaltan etkenlerdir (Jackson ve Searle, 1985).

Covid-19 döneminde şüphesiz ki fiziksel aktiviteye kat1lımın engellenmesi konusundaki en belirgin etkenin mevcut virüs 
olduğu savunulabilir (Du et al., 2020; Kim, Cho ve Park, 2020). Diğer yandan engelleyici faktörler arasında; cinsiyet, gelir durumu, bireyin fizyolojik yapısı, ulaşılabilirlik, maliyet, zaman, tesis ve sosyal izolasyon durumları da etkili olmaktadır (Andrade et al., 2019; Kim et al., 2020; Jackson, Henderson ve Henderson, 1995).

Araştırmalar Covid-19 sürecinden önce fiziksel aktiviteye katılım oranlarının bu sürece kıyasla çok daha yüksek olduğunu vurgulamaktadir (Stockwell et al., 2021). Dünya Sağlık Örgütü (WHO) ise mevcut virüsün etkilerinin azaltılmasında, haftada 5 gün 30 dakika olacak şekilde fiziksel aktiviteye katılım gösterilmesini önermektedir (WHO, 2021; WHO, 2020).

Covid-19 sürecinde rekreasyon alanlarının ön plana çıkması ve bu süreçle birlikte değişen yaşam tarzları göz önüne alındığında fiziksel aktivite amaçlı rekreasyon alanların kullanımını incelemek bir zaruret unsuru olarak ortaya çıkmaktadır.

\section{Araştırmanın Amacı}

$\mathrm{Bu}$ çalışmanın amacı Covid-19 sürecinde fiziksel aktivite amacıyla açık rekreasyon alanlarını tercih eden bireylerin mekan seçimi ve fiziksel aktiviteye katılımını etkileyen faktörlerin tespit edilmesidir. Bu kapsamda fiziksel aktivite amacıyla mekan seçimi ve katılım engelleri; cinsiyet, medeni durum, eğitim, yaş ve gelir durumu değişkenlerine göre incelenecektir.

\section{YÖNTEM}

Çalışma nicel araştırma modelinden betimsel tarama desenine göre yürütülmüştür. Betimsel tarama; mevcut durumun fotoğrafını çekmek için gerçekleştirilen, katılımcıların görüştutum-davranış ve ilgi gibi özelliklerini anketler aracılığ 1 ile ölçmeye çalışan araştırmalardır (Demirel, 2018; Gürbüz ve Şahin, 2017).

\section{Evren ve Örneklem}

Araştırmanın evrenini Konya ilinde ikamet eden, yüz yüze anket tekniği kullanılarak il merkezinde bulunan parklara (Alaaddin Tepesi Park1, Nene Hatun Park1, Bosna Hersek Cumhuriyet Parkı ve Japon Parkı) rekreasyonel fiziksel aktivite amaçlı katılım gösteren 18-65 yaş arası yetişkinler oluşturmaktadır. Konya'nın kullanıcı yoğunluğu bakımından en büyük parkları bu araştırma kapsamında seçilmiştir. Nicel araștırma olarak tasarlanan bu çalıșmada betimsel tarama deseni kullanılmakla birlikte örnekleme yöntemi olarak olasılıksız örnekleme yöntemlerinden kolayda örneklem seçilmiştir. Örneklem büyüklüğünü hesaplamak için "G-Power 3.1.9.4" paket programı kullanılmış ve etki büyüklüğü olarak iki değişkenli bağımsız değişkenler için her grupta 88 kişi olmak üzere totalde 176 kişilik 2 grup yeterli olarak tespit edilmiştir (etki boyutu 0.5 ; hata payı 0.05 ; güven aralığ1 0.95). Araştırma kapsamında 624 kişiye ulaşılmış, eksik ve yanlış doldurulmuş formlar çıkarıldıktan sonra örneklem için 450 kişiden elde edilen veriler kullanılmıștır. Bu çalıșma Selçuk Üniversitesi etik kurul komisyonu (E.95178 karar numarası ile) tarafindan onaylanmıştır.

\section{Veri Toplama Araçları}

Çalışmanın verileri Stanis et al. (2009) tarafindan geliştirilen, Gümüş, Alay ve Karakılıç (2015) Türkçeye uyarladığı "Fiziksel Aktivite Mekânı Değerlendirme (FAMDÖ)" ölçeği kullanılarak elde edilmiștir. 26 maddeden oluşan ölçek; "Fiziksel Aktivite Mekânı Seçimi (FAMS)" ve "Fiziksel Aktiviteye Katılımı Engelleyen Unsurlar (FAKE)" olarak 2 alt boyuttan oluşmaktadır. FAMS alt boyutu 11 maddeden, FAKE alt boyutu ise 15 maddeden meydana gelmektedir.

Türkçe geçerlilik ve güvenilirlik çalışmasını gerçekleştiren Gümüş ve diğerlerinin (2015) yapmış olduğu çalışmada Cronbach Alpha iç tutarlılık katsayıları FAMS alt boyutu için .82, FAKE alt boyutu için .91 olarak tespit edilmiștir. Ișıkgöz ve diğerleri (2017) yapmıș olduğu çalışmada ise, FAMS alt boyutu için .72, FAKE alt boyutu için .86 değerini tespit etmişlerdir. Bundan dolayı, bu çalışmada kullanılan ölçeklerin güvenilirliği test etmek için Cronbach Alpha tercih edilmiştir. FAMS alt boyutu için güvenilirlik katsayısı .75, FAKE alt boyutu için .70 olarak tespit edilmiştir. 
Aksu, H.S., Kaya, A., Arslan, F./Covid-19 Sürecinde Fiziksel Aktivite Amacıyla Açık Rekreasyon Alanlarını Tercih Eden Bireylerin Mekân Seçimi ve Fiziksel Aktiviteye Katılımını Etkileyen Faktörler

\section{İslem}

Veri toplamak için oluşturulan formlar Aralık 2020 tarihinde Konya il merkezinde ki parklardan elde edilmiştir. Gönüllü katılım ilkesi ile çalışma katılımcılara uygulanmıştır.

\section{Verilerin Analizi}

Veriler açık kaynak kod yazılımlı Jamovi 1.6.9.0. paket programı kullanılarak analize tabi tutulmuştur. Analiz kısmında demografik faktörler için betimsel istatistik metotları yüzde \%, frekans (n), standart sapma (Ss) ve aritmetik ortalama kullanılmıştır. Verilerin homojen dağılıp dağılmadığı tespit etmek maksadıyla çarpıklık ve basıklık değerlerine bakılmıştır.

Analiz sonucunda FAMS ve FAKE alt boyutu için çarpıklık ve basıklık test sonuçları Tablo 1 'de sunulmuştur. George (2011) bu değerlerin \pm 2 arasında olmasının parametrik testlerin yapılması için yeterli bir gösterge olduğunu belirtmektedir. Bu sebeple, FAMS ve FAKE alt boyutlarında etkili olan nedenleri test etmek maksadıyla cinsiyet ve yaş durumuna göre anlamlı bir farkl111k olup olmadığını ölçmek için bağımsız örneklemler t-testi; eğitim durumu, medeni durum ve gelir seviyesine göre anlamlı bir farklılik olup olmadığını ölçmek için ise tek yönlü varyans analizi (ANOVA) kullanılmıştır.

Tablo 1. Çarpılık-Basıklık Değerleri

\begin{tabular}{llcc}
\hline \multirow{3}{*}{ FAMS } & & \multicolumn{2}{c}{ Standart } \\
& & İstatistik & Hata \\
\cline { 2 - 4 } & Çarpıklık & 0,478 & 0,115 \\
\cline { 2 - 4 } & Basıklık & $-1,073$ & 0,230 \\
\hline \multirow{2}{*}{ FAKE } & Çarpıklık & $-0,402$ & 0,115 \\
\cline { 2 - 4 } & Basıklık & $-0,702$ & 0,230 \\
\hline
\end{tabular}

\section{BULGULAR}

Katılımciların demografik bilgilerini incelendiğinde (Tablo 2.) 450 katılımcının $\% 56$ 'sının erkek olduğu, yaş aralıklarının $\% 73$ oranında 26 ila 45 yaş arasında değiştiği, evli bireylerin oranının \%56,2 olduğu, eğitim seviyelerinin $\% 70$ oranında lise ve ön lisans olduğu, gelir seviyesinin ise $\% 70$ oranında 2001 - 4000 TL arasında değiştiği görülmektedir.
Tablo 2. Demografik Bilgilere Yönelik Değişkenler

\begin{tabular}{|c|c|c|c|}
\hline Değişken & & $\mathbf{n}$ & $\%$ \\
\hline \multirow{2}{*}{ Cinsiyet } & Erkek & 254 & 56,4 \\
\hline & Kadın & 196 & 43,6 \\
\hline \multirow{4}{*}{ Yaş } & $18-25$ & 86 & 19,1 \\
\hline & $26-35$ & 203 & 45,1 \\
\hline & $36-45$ & 126 & 28 \\
\hline & $46-65$ & 35 & 7,8 \\
\hline \multirow{2}{*}{$\begin{array}{l}\text { Medeni } \\
\text { Durum }\end{array}$} & Evli & 253 & 56,2 \\
\hline & Bekar & 197 & 43,8 \\
\hline \multirow{4}{*}{$\begin{array}{l}\text { Eğitim } \\
\text { Durumu }\end{array}$} & İlkokul & 64 & 14,2 \\
\hline & Lise & 164 & 36,4 \\
\hline & Ön Lisans & 151 & 33,6 \\
\hline & Lisans & 71 & 15,8 \\
\hline \multirow{5}{*}{$\begin{array}{l}\text { Gelir } \\
\text { Seviyesi }\end{array}$} & $2001 \mathrm{TL}-$ & 47 & $10 \%$ \\
\hline & $2001-3000 \mathrm{TL}$ & 139 & $31 \%$ \\
\hline & $3001-4000 \mathrm{TL}$ & 151 & $34 \%$ \\
\hline & $4001-5000 \mathrm{TL}$ & 77 & $17 \%$ \\
\hline & $5001 \mathrm{TL}+$ & 36 & $8 \%$ \\
\hline
\end{tabular}

Tablo 3. FAMS Alt Boyutuna İlişkin Betimleyici Bulgular

\begin{tabular}{|c|c|c|c|}
\hline & & Ort. & $\begin{array}{c}\text { Std. } \\
\text { Sapma }\end{array}$ \\
\hline 1 & $\begin{array}{l}\text { Düz yürüyüş / Gezi } \\
\text { / Bisiklet parkuru }\end{array}$ & 1,59 & 0,56 \\
\hline 2 & $\begin{array}{l}\text { Suç ortamından } \\
\text { uzak durma hissi }\end{array}$ & 1,73 & 0,45 \\
\hline 3 & $\begin{array}{l}\text { Sakatlanma riskinin } \\
\text { olmaması }\end{array}$ & 1,86 & 0,76 \\
\hline 4 & Kolay ulaşım & 1,79 & 0,48 \\
\hline 5 & Işıklandırma & 4,19 & 0,57 \\
\hline 6 & Çeşmeler / Kaynak suyu & 1,86 & 0,66 \\
\hline 7 & Tuvaletler & 1,57 & 0,50 \\
\hline 8 & $\begin{array}{l}\text { Tesisin temizliği } \\
\text { (örn. Tuvaletler) }\end{array}$ & 4,70 & 0,45 \\
\hline 9 & $\begin{array}{l}\text { Bakımlı olması } \\
\text { (örn., Çeşmelerin } \\
\text { çalışması) }\end{array}$ & 1,63 & 0,52 \\
\hline & Mekânın güzel olması & $\mathbf{4 , 5 7}$ & 0,51 \\
\hline & Eve yakınlığ1 & 2,10 & 0,66 \\
\hline
\end{tabular}

FAMS alt boyutuyla ilgili "Tesisin temizliği (örn. Tuvaletler)" ifadesi en yüksek $(4,70)$, "Tuvaletler" ifadesi de en düşük $(1,57)$ seçme nedenine sahip oran olduğu görülmektedir. 
Aksu, H.S., Kaya, A., Arslan, F./Covid-19 Sürecinde Fiziksel Aktivite Amacıyla Açık Rekreasyon Alanlarını Tercih Eden Bireylerin Mekân Seçimi ve Fiziksel Aktiviteye Katılımını Etkileyen Faktörler

Tablo 4. FAKE Alt Boyutuna İlişkin Betimleyici Bulgular.

\begin{tabular}{|c|c|c|c|}
\hline & & Ort. & $\begin{array}{l}\text { Std. } \\
\text { Sapma }\end{array}$ \\
\hline 1 & $\begin{array}{l}\text { Suça meyilli kişilerin } \\
\text { buraya gelmesi }\end{array}$ & $\mathbf{1 , 5 0}$ & 0,54 \\
\hline 2 & $\begin{array}{l}\text { Alkol tüketenlerin } \\
\text { bulunması }\end{array}$ & $\mathbf{1 , 5 0}$ & 0,59 \\
\hline 3 & Soyulma korkusu & 2,01 & 0,75 \\
\hline 4 & Fiziksel saldırı korkusu & 1,81 & 0,92 \\
\hline 5 & Irkçı saldırı korkusu & 3,38 & 0,86 \\
\hline 6 & Cinsel-saldırı korkusu & 2,74 & 1,26 \\
\hline 7 & $\begin{array}{l}\text { Etraftaki insanların } \\
\text { ilgisizliği(mekânın } \\
\text { kullanıcıları, } \\
\text { varsa çalışanlar gibi) }\end{array}$ & 1,76 & 0,47 \\
\hline 8 & Maddi yetersizlik & 4,00 & 0,54 \\
\hline 9 & Işıklandırma yetersizliği & 2,07 & 0,42 \\
\hline 10 & Dermansızlık/ enerjisizlik & 1,80 & 0,56 \\
\hline 11 & $\begin{array}{l}\text { Buranın, evime yeterince } \\
\text { yakın olmaması }\end{array}$ & 2,05 & 0,73 \\
\hline 12 & $\begin{array}{l}\text { Buranın istediğim } \\
\text { faaliyetleri } \\
\text { sunmaması }\end{array}$ & 4,12 & 0,37 \\
\hline 13 & $\begin{array}{l}\text { Burada yeterince ağaç } \\
\text { ve çim 'in olmaması }\end{array}$ & 4,56 & 0,57 \\
\hline 14 & $\begin{array}{l}\text { Buranın çok kalabalık } \\
\text { olması }\end{array}$ & 1,83 & 0,51 \\
\hline 15 & $\begin{array}{l}\text { Buraya toplu taşımanın } \\
\text { olmaması (otobüs, } \\
\text { dolmuş ve metro/tren gibi.) }\end{array}$ & 2,22 & 0,56 \\
\hline
\end{tabular}

FAKE alt boyutu ile ilgili "Burada yeterince ağaç ve çim 'in olmaması" en yüksek $(4,56)$ ortalamaya sahipken, "Suça meyilli kișilerin buraya gelmesi" $(1,50)$ ve "Alkol tüketenlerin bulunması" $(1,50)$ en düşük ortalamaya sahip olduğu görülmektedir (Tablo 4).

Bağımsız örneklemler t-testi sonucuna göre, kadınların $(2,59)$ FAMS puanlarının erkeklere $(2,43)$ göre anlamlı bir farkl111k gösterdiği görülmektedir $\left(\mathrm{t}_{(-5,55)}=\mathrm{p}<0,05\right)$. FAKE alt boyutu için ise kadınlar $(2,60)$ ile erkekler $(2,48)$ arasında anlamlı bir farklılık $\left(\mathrm{t}_{(9.84)}=\mathrm{p}\right.$ $<0,05$ ) olduğu anlaşılmaktadır (Şekil 1).

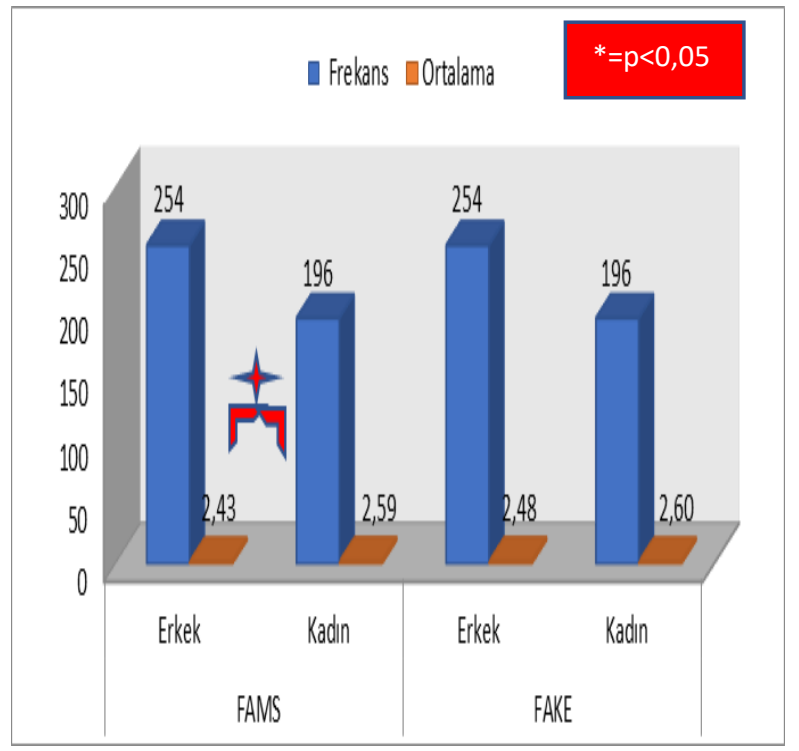

Şekil 1. Mekân seçim ölçek Puanlarının Cinsiyete Göre T-testi Sonuçları

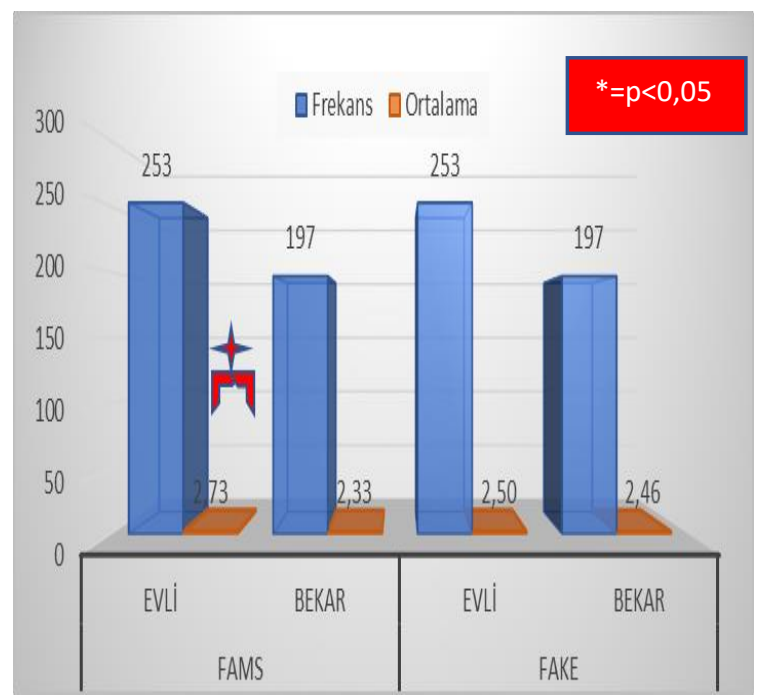

Şekil 2. Mekân seçim ölçek Puanlarının Medeni Duruma Göre T-testi Sonuçları

Bağımsız örneklemler t-testi sonucuna göre, bekârların $(2,73)$ FAMS puanlarının, evlilere göre $(2,33)$ anlamlı bir farklılık gösterdiği görülmektedir $\left(\mathrm{t}_{(-18,68)}=\mathrm{p}<0,05\right)$. FAKE alt boyutunda ise medeni duruma göre anlaml bir farklılık tespit edilememiştir $\left(\mathrm{t}_{(1,35)}=\mathrm{p}\right.$ > $0,05)$. 


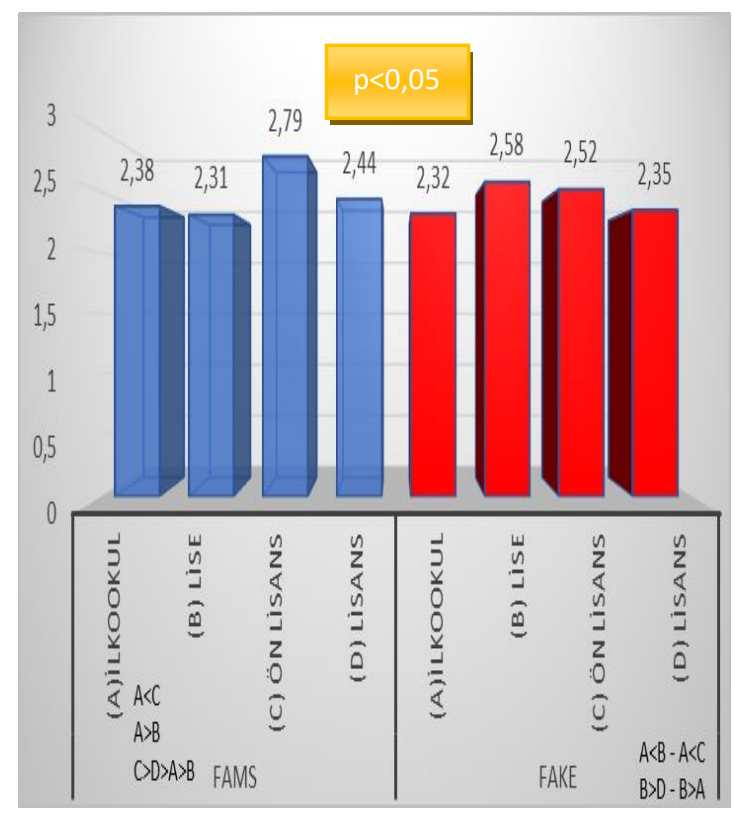

Şekil 3. Mekân seçimi ölçek puanlarının eğitim durumuna göre ANOVA sonuçları.

Bireylerin oluşturduğu eğitim durumu değişkenleri incelendiğinde İlkokul mezunu (64), Lise mezunu (161), Ön Lisans mezunu (151), Lisans mezunları (71) kişiden oluşmaktadır. Anlamlı farklılığın hangi gruplar arasında gerçekleştiğini saptamak amaciyla ANOVA Post Hoc Games-Howell testi yapılmıştır. Test sonucunda mekan seçiminde önemli olarak görülen hususlar; İlkokul eğitim düzeyine sahip bireyler $(2,38)$ ile Ön lisans $(2,79)$ ve Lise $(2,31)$; Ön Lisans $(2,79)$ eğitimine sahip bireyler ile Lisans $(2,44)$ eğitim düzeyi sahip bireyler arasında anlamlı bir farklılık görülmektedir. Yani eğitim düzeyi mekan seçiminde etkili olan bir husus olarak ortaya çıkmaktadır.

Fiziksel aktiviteye kat1lımı engelleyen unsurlar ise; yine İlkokul $(2,32)$ ile Lise $(2,58)$ ve Ön Lisans $(2,52)$; Lise $(2,58)$ ve Lisans $(2,35)$ eğitim düzeyine sahip gruplar arasında anlamlı bir farklılık göstermektedir. Yani fiziksel aktivite amacıyla mekân seçiminde engelleyici unsurlar eğitim seviyesine göre farklılaşmaktadır.

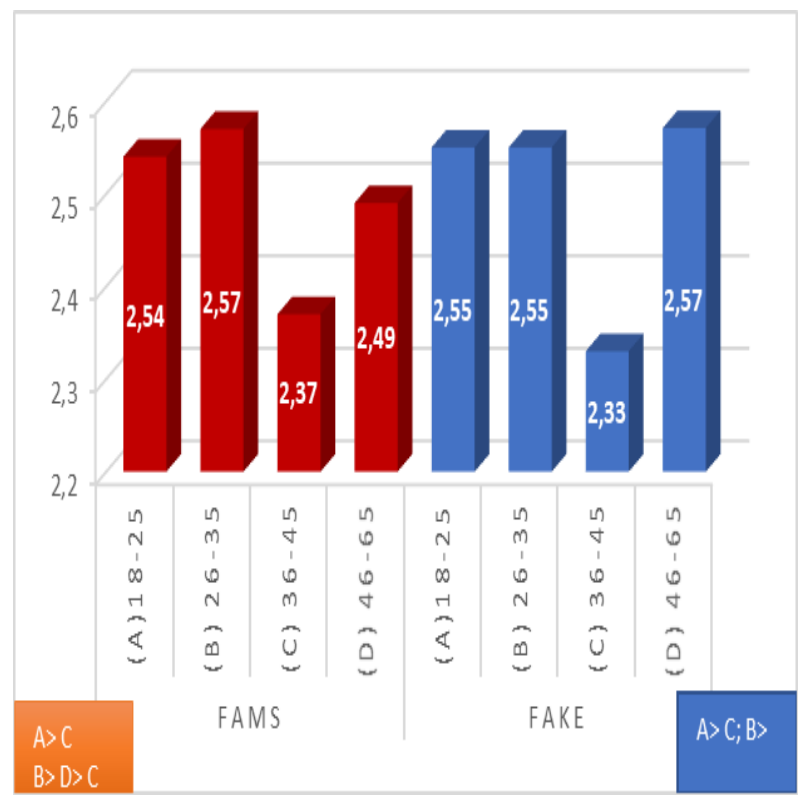

Şekil 4. Mekân seçimi ölçek puanlarının yaş durumuna göre ANOVA sonuçları.

Bireylerin yaş durumuna göre gerçekleştirilen ANOVA testi sonucunda; FAMS puanları ( $p$ $<0,05)$ ve FAKE puanlar1 $(\mathrm{p}<0,05)$ arasinda anlamlı bir farklılık ortaya çıkmıştır. Test sonucuna göre FAMS alt boyutunda anlaml farkl1l1k; 18 - 25 yaş grubu $(2,54)$ ile $36-45$ $(2,37)$ yaş grubu arasında; 26 - 35 yaş grubu $(2,57)$ ile hem $46-65$ yaş grubunda $(2,49)$ hem de 36 - $45 \quad(2,37)$ yaş grubu arasındadir. FAKE alt boyutunda ise anlamlı farklılik; yine 18 - 25 yaş grubu $(2,55)$ ile $36-45$ $(2,33)$ yaş grubu arasında; ayrıca $26-35$ yaş grubuyla $(2,55)$ hem $46-65$ hem de $36-45$ $(2,33)$ yaş grubu arasındadır.

Gelir durumu baz alınarak yapılan test sonucunda; fiziksel aktivite amaciyla mekan seçim kriterleri gelir durumuna göre farklılaşmadığı sonucuna ulaşılmaktayken, katılımı engelleyici unsurlar gelir durumuna göre farklılaşmaktadır. Bu farklılık 2001-3000 TL $(2,54)$ gelir grubu ile 3001-4000 TL $(2,42)$ gelir grubuna sahip bireyler arasinda görülmektedir (Şekil 5). 


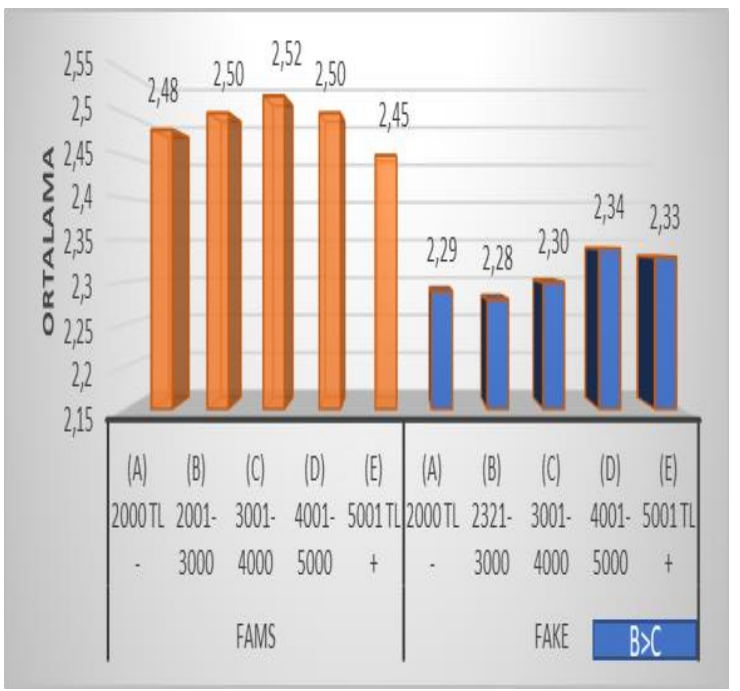

Şekil 5. Mekân seçim ölçek Puanlarının Gelir Duruma Göre T-testi Sonuçları

\section{TARTIŞMA ve SONUÇ}

$\begin{array}{lcc}\text { Rekreasyon } & \text { faaliyetlerine kat1lım } \\ \text { motivasyonları } & \text { ve kıstlayiciların }\end{array}$ ölcümlendiği calısmalarda amac kullaniciları rekreasyonel etkinliklere ya da bu etkinlikleri gerçekleştirecekleri alanlara katılımını arttıran veya engelleyen unsurları tespit edebilmektir. $\mathrm{Bu}$ çalışmada, bireylerin Fiziksel Aktivite Mekan Seçim unsurları ve Fiziksel Aktivite Katılım Engelleyicileri unsurlar1; cinsiyet, medeni durum, yaş, gelir durumu ve eğitim durumları açısından incelenmiş̧tir.

Yapilan inceleme sonucunda cinsiyet ile hem FAMS hem de FAKE alt boyutu açısından anlamlı bir farklılık tespit edilmiştir. Çalışmada kadınların fiziksel aktivite amacıyla mekân seçim algılarının daha yüksek olduğu sonucu elde edilmiştir. Mekân seçiminde önemli faktörler arasında tesisin temizliği, mekanın güzel olması ve 1şıklandırma ifadeleri dikkat çekmektedir. Tesis temizliği ve mekân güzelliği beklenen bir sonuç olmakla birlikte, 1şıklandırma ortalamasının yüksek olması kadınların güvenlik unsuruna dikkat ettiği anlamında düşünülmektedir. Rekreasyon alanlarının tercihinde kişisel güvenliğin mekân seçiminde önemli olduğunu gösteren birçok çalışma vardır (Aşıkkutlu, 2008; Gümüş ve diğerleri, 2017; Hudson, 2000; Johnson, Bowker ve Cordell, 2001; Raymore, Godbey ve
Crawford, 1994; Jackson ve Searle, 1985; Shores, Scott ve Floyd, 2007). Özellikle kadın kullaniciların rekreasyon aktivitelerini gerçekleştirmek için kullandıkları alanların daha hijyenik olması, mekanın rahatlatıcı ve güvenli olması ve iyi ş̧ıklandırılması yeni yapılacak alanlarda bu hususa dikkat edilmesi, kadınların rekreasyonel faaliyetlere katılımını arttırabilir. FAKE alt boyutunda ki anlamlı farklılık kadınların erkeklere oranla daha çok engel ile karşılaşması yönündedir. $\mathrm{Bu}$ durumum sebebinin kadınlarının günlük yaşam içerisinde üstlenmiş oldukları rollerden (annelik, temizlik, ev idaresi gibi) kaynaklandığı düşünülmektedir. Rekreasyon faaliyetlerine katılımda kadınların erkeklere göre dezavantajlı olduğunu, bu dezavantajın günlük sorumluluklardan (çocuk bakımı, ev işleri gibi) kaynaklandığını gösteren birçok çalışma vardır (Ardahan ve Lapa, 2011; Floyd et al., 2006; Henderson ve Dialeschki, 1991; Lee, Scott ve Floyd, 2001). Önceki araştırmalarda elde edilen sonuçlar ile bu araştırmanın bulguları paralellik göstermektedir.

Araştırmada rekreasyonel alanlara katılım gösteren bireylerin medeni durumları değişkeni göz önünde bulundurulduğunda FAMS alt boyutunda istatistiksel olarak anlamlı farkl1l1k gözlemlenirken; FAKE alt boyutunda ortalamalar arasinda fark olup istatistiksel olarak anlamlılık olmadığı tespit edilmiştir. FAMS alt boyutundaki anlamlı farklılığın olmas1 ve bekar bireylerde daha yüksek bir ortalamanın tespit edilmesinde ki nedenin; fiziksel aktivite amaçlı rekreasyona katılımda bekar bireylerin evli bireylere kıyasla daha az sorumluluğa sahip olmalarından kaynaklandığı düşünülmektedir. Armutcu (2018) yapmış olduğu çalışmada rekreasyon faaliyetlerine kat1lımda bekar bireylerin daha az engel ile karşılaştığı ve bunun sebebinin evli bireylerin bekarlara oranla daha çok sorumluluğa sahip olmalarından kaynaklandığ 1 vurgulamaktadır. FAKE alt boyutunda ortalamalar arasindaki farklı1ığın evli bireylerde daha yüksek olması, evli bireylerin faaliyete katılım konusunda daha fazla engel ile karşılaşmaları anlamına gelmektedir. $\mathrm{Bu}$ durumun sebep olan faktörün, evli bireylerin bekâr bireylere kıyasla sorumluluklarının (ev işleri - çocuk 
bakımı - yemek yapma ve aile olmanın getirdiği diğer sorumluluklar) daha fazla olmasından kaynaklandığı düşünülmektedir.

Araştırmada eğitim değişkenine göre hem FAMS hem de FAKE alt boyutlarının anlamlı bir şekilde farklılaştığ FAMS alt boyutu için İlkokul, lise ve ön lisans eğitim düzeyine sahip bireyler arasında anlamlı farklılık görülmektedir. FAMS alt boyutunda ki anlamlı farklılığın en yüksek Ön lisans düzeyinde görülmesinin nedeninin eğitim seviyesi ile rekreasyon faaliyetlerine katılım arasında pozitif yönde bir ilişki olmasından kaynaklandığı düşünülmektedir. Jackson ve Searle (1985) rekreasyon kısıtlayıcıları üzerine yapmış oldukları çalışmada, eğitim seviyesi arttıkça kısıtlayıcıların etkisinin azaldığı yönünde bir sonuca ulaşmıştır; Todd et al. (2001), eğitim seviyesi ile fiziksel aktivite amaciyla mekan seçimi arasında anlamlı bir ilişki tespit etmektedir. Aşıkkutlu (2008) ise, rekreasyon faaliyetlerinde motivasyon ve kisitlayıcılar üzerine yaptığ 1 çalışmada eğitim seviyesi ile kısıtlayıcılar arasında negatif bir ilişkiye (eğitim seviyesi arttıkça kısıtlayıcıların azalması) dikkat çekmektedir. Gümüş ve diğerleri (2017) ise, aktivitelere katılımını engelleyen unsurlar ile eğitim düzeyi arasında ters yönlü bir ilişki (eğitim seviyesi arttıkça kısıtlayıcıların azalması) tespit etmiştir. Armutcu (2018) ise, fiziksel aktivite amaçlı park ve rekreasyon alanlarının kullanımını etkileyen faktörleri incelediği çalışmada eğitim düzeyi yükseldikçe rekreasyon alanlarına katılımın arttığı tespit edilmiştir. Araştırmalarda elde edilen sonuçlar, yapılan bu çalışmada elde edilen sonuçlar ile paralellik göstermektedir. FAKE alt boyutu için anlamlı farklılık en yüksek lise düzeyinde, en düşük ise İlkokul düzeyinde görülmektedir. Bunun sebebinin Covid-19 sürecinde daha yüksek eğitim seviyesine sahip bireylerin daha endişeli davranarak boş zamanlarında olabildiğince kendilerini izole etmeye çalıştıklarından kaynaklandığı düşünülmektedir. Toprakçı, Toprakçı ve Meşe (2019) 9 ayrı çalışmadan elde ettikleri, örneklem büyüklügünün 521.900 olduğu eğitim ve sağlık arasında ki ilişkiyi belirledikleri çalışmada, bireylerin eğitim seviyeleri arttıkça, sağlıklarına olan düşkünlüklerinin de arttığını vurgulamaktadırlar. Elde edilen bu sonuç, araştırma bulgusunu destekler niteliktedir.

Çalışmada FAMS ve FAKE ölçek puanlarının yaş değişkenine göre anlamlı bir şekilde farklılaştığı tespit edilmiştir. FAMS alt boyutunda en yüksek ortalamaya sahip grubun 26-35 ve 18-25 yaş grubuna ait bireyler olduğu görülmektedir. Bunun sebebinin genç bireylerin salgın döneminde dahi fiziksel aktiviteye katılım gösterme ve mekan seçiminde özen ve itinalı davranmalarından, sağlık açısından fiziksel aktivite ve mekan seçiminin öneminin farkında olmalarından kaynaklandığı düşünülmektedir. FAKE alt boyutundan elde edilen bulgularda da en yüksek ortalama 46-65 yaş grubunda görülmektedir. Bunun sebebinin bireyin yaş alması sonucunda fiziksel aktiviteden uzaklaşma eğilimi olduğu düşünülmektedir. Torkildsen (2005), yaş faktörünün rekreasyon faaliyetlerine katılımı direkt etkileyen bir unsur olduğunu, bireyin yaşlandıkça fiziksel aktivite amaçlı rekreasyon faaliyetlerine daha az katılım göstereceğini vurgulamaktadır. Kelly (1983) çalışmasında birey yaş aldıkça, aktif olarak rekreasyon faaliyetlerine katılim düzeyinin azaldığını belirtmektedir. Yapılan bu çalışmalar elde edilen bulguyu destekler niteliktedir.

Araştırmanın bir diğer bulgusuna göre, FAMS alt boyutu ile gelir durumu arasinda anlaml bir farklılık tespit edilememiştir. Öte yandan FAKE alt boyutu için anlamlı farklılık 20013000 TL gelir durumuna sahip bireyler ile 3001- 4000 TL gelir durumuna sahip bireyler arasında görülmektedir. Yani $2001-3000$ TL arasinda gelir durumuna sahip bireyler daha fazla kısıtlayıcı ile karşılaşmaktadır. Johnson et al. (2001) rekreasyon kısitlayıciları üzerine yapmış oldukları çalışmada en belirgin kısıtlayıcının gelir düzeyi olduğunu, en düşük gelir düzeyine sahip grubun en fazla kısıtlayıcı ile karşılaştığını vurgulamaktadırlar. Alexandris ve Carroll (1997), yaptıkları çalışmada $18-25$ yaş arası gençlerin alanın erişebilir olması ve finansal yetersizlikten kaynaklı tüm yaş grupları arasinda (18-25, 26-35, 36-45, 46-65) en yüksek ortalamaya sahip olduğunu tespit etmişlerdir. Chick et al. (2015) yapmış oldukları çalışmada ekonomik yetersizliğin 
rekreasyon faaliyetlerine katılımı olumsuz yönde etkilediğini vurgulamaktadır. $\mathrm{Bu}$ durumun sebebinin bireyin öncelikleri arasında ilk olarak hayatını idame ettirebilmek için ekonomik gelir elde etmek ve sonra ki aşamada rekreasyonel anlamda fiziksel aktiviteye katılmak olduğu düşünülmektedir.

Covid-19 sürecinin devam ettiği bu günlerde sağlıkla ilgili rekreasyonel uygulamalar önem kazanmış ve açık alan rekreasyon alanlarına olan talebinde arttığı gözlemlenmiştir (Jackson et al., 2021; Nathan et al., 2021; Onur, 2020). Araştırma sonucunda elde edilen bulgular fiziksel aktivite amaçlı rekreasyon alanlarının tercihinde alanın temizliği, 1şıklandırma ve alanın bakımlı olmasının, alan tercihinde etkili faktörlerin temizlik ve güvenlik unsurunda birleştiğini göstermektedir. Alan tasarımında ya da alanın iyileştirilme çalışmalarında bu hususlara dikkat edilmesi fiziksel aktivite amacıyla açık alanların daha çok tercih edilmesine dolayısıyla halk sağlığına katkı sağlayacağı düşünülmektedir. Araştırmadan elde edilen bir diğer sonuca göre; fiziksel aktivite amaçlı alan seçiminde, mekanın yeterince ağaçlı olmamasının en etkin kısıtlayıcı olduğu tespit edilmiştir.

Mevcut rekreasyon alanlarında ağaçlandırma çalışmaların yapılması ya da peyzaj çalışmaların arttırılması, bu alanlarının tercih edilmesinde etkili olacağı ve böylece fiziksel aktivite aracılığıyla toplum sağlığına katkı sağlanabileceği düşünülmektedir. $\mathrm{Bu}$ ve benzeri çalışmalar sonucunda bireylerin rekreasyon alanlarından beklentileri tespit edilebilmekte ve zaman içerisinde karşılaştırmalara da gidilebilmektedir. $\mathrm{Bu}$ sayede yerel yönetimler ve rekreasyon yöneticileri, rekreasyon alanlarının gerek tasarımlarında gerekse düzenlemelerinde bu tür verileri dikkate alıp gerekli düzenlemeleri ya da eylem planlarını gerçekleştirebilecektir.

$\mathrm{Bu}$ araştırma kapsamında yalnızca Konya ili ele alınmış olmakla birlikte, gelecek çalışmalar farklı şehirleri ya da bölgeleri kapsayacak şekilde genişletilebilir.

\section{Yazarların Makaleye Katkı Beyanı}

Makale tasarımı, literatür taraması, makale yazımı, dergi yazım kurallarına uygun şekilde düzenlenerek gönderilmesi Hasan Suat Aksu, Alper Kaya ve Fatma Arslan tarafindan yapılmıştır.

\section{Çıkar Çatışması}

Yazarların beyan edecek herhangi bir çıkar çatışması yoktur.

\section{Finansal Destek}

$\mathrm{Bu}$ çalışmanın yapılabilmesi için herhangi bir finansal destek alınmamıştır.

\section{Etik Kurul Onayı}

Bu çalışma Helsinki bildirgesi ile uyumludur. Çalışma Selçuk üniversitesi Sosyal ve Beşeri Bilimler Bilimsel Araştırma ve Yayın Etiği Kurulundan onaylidır (11/12/2020-E.100752).

\section{Hakem Değerlendirmesi}

Kör hakemlik süreci sonrası yayınlanmaya uygun bulunmuş ve kabul edilmiştir.

\section{KAYNAKÇA}

Alexandris, K., ve Carroll, B. (1997). Demographic differences in the perception of constraints on recreational sport participation: results from a study in Greece. Leisure Studies, 16(2), 107-125. https://doi.org/10.1080/026143697375449

Andrade, R. D., Junior, G. J. F., Capistrano, R., Beltrame, T. S., Pelegrini, A., Crawford, D. W., ve Gomes Felden, É. P. (2019). Constraints to leisure-time physical activity among Brazilian workers. Annals of Leisure Research, 22(2), 202-214. https://doi.org/10.1080/11745398.2017.14 16486

Ardahan, F., ve Lapa, T. Y. (2011). Açık alan rekreasyonu: bisiklet kullanıciları ve yürüyüş̧̧̈lerin doğa sporu yapma nedenleri ve elde ettikleri faydalar. Uluslararası Insan Bilimleri Dergisi, 8(1), 1329-1341.

Armutcu, F. (2018). Fiziksel Aktivite Amaçlı Park ve Rekreasyon Alanlarinin Kullaniminı Etkileyen Faktörlerin Belirlenmesi. Yayımlanmamış yüksek lisans tezi, Batman Ü. Sosyal Bilimleri Enstitüsü, Batman. 
Aş1kkutlu, H. S. (2008). Rekreasyonel Motivasyon ve Kisitlayıcılar; Ankara Göksu Parkı ve Harikalar Diyarl Parkı Örneği. Yayımlanmamış Yüksek Lisans Tezi, Düzce Üniversitesi, Peyzaj Mimarlığı Anabilim Dalı, Düzce.

Bayram, A. T., \& Kavlak, H. T. (2021). Rekreasyon ve Teknoloji. S. Gül Güneş \& F. Varol, (Ed.). Rekreasyon: Disiplinlerarası Yaklaşım ve Örnek Olaylar içinde (ss. 383 -402). Ankara: Nobel Kitabevi.

Brown, R. A., Abrantes, A. M., Minami, H., Read, J. P., Marcus, B. H., Jakicic, J. M., Strong, D. R., Dubreuil, M. E., Gordon, A. A., Ramsey, S. E., Kahler, C. W., ve Stuart, G. L. (2014). A preliminary, randomized trial of aerobic exercise for alcohol dependence. Journal of Substance Abuse Treatment, 47(1), 1-9. https://doi.org/10.1016/j.jsat.2014.02.004

Burtscher, J., Burtscher, M., ve Millet, G. P. (2020). (Indoor) isolation, stress, and physical inactivity: Vicious circles accelerated by COVID-19? Scandinavian Journal of Medicine \& Science in Sports, $30(8)$, 1544-1545. https://doi.org/10.1111/sms.13706

Cairney, J., Dudley, D., Kwan, M., Bulten, R. ve Kriellaars, D. (2019). Physical Literacy, Physical Activity and Health: Toward an Evidence-Informed Conceptual Model. Sports Medicine içinde (C. 49, Sayı 3, ss. 371-383). Springer International Publishing.

Caspersen, C., Powell, K. (1985). Physical activity, exercise, and physical fitness: definitions and distinctions for healthrelated research. Public Health Rep, 1(2), 126-131.

Chick, G., Hsu, Y.-C., Yeh, C.-K., ve Hsieh, C.-M. (2015). Leisure Constraints, Leisure Satisfaction, Life Satisfaction, and SelfRated Health in Six Cities in Taiwan. Leisure Sciences, 37(3), 232-251. https://doi.org/10.1080/01490400.2014.96 7897

Crisafulli, A., ve Pagliaro, P. (2020). Physical activity/inactivity and COVID-19. European Journal of Preventive Cardiology, 204748732092759. https://doi.org/10.1177/204748732092759 7

Çuhadar, A., Yusuf, E. R., Demirel, M., \& Demirel, D. H. (2019). Bireyleri rekreasyonel amaçlı egzersize motive eden faktörlerin incelenmesi. Spormetre Beden
Eğitimi ve Spor Bilimleri Dergisi, 17(3), 153-161.

Demirel, E. T. (2018). Sosyal Bilimlerde Araştırma Yöntemleri: Tasarımlar için bir rehber (Ş. ASLAN (ed.)). Eğitim Yayınevi.

Du, J., Floyd, C., Kim, A. C. H., Baker, B. J., Sato, M., James, J. D., ve Funk, D. C. (2020). To be or not to be: negotiating leisure constraints with technology and data analytics amid the COVID-19 pandemic. Leisure Studies, 00(00), 1-14. https://doi.org/10.1080/02614367.2020.18 $\underline{62284}$

Elnaggar, R. K. (2021). Within 5-year off-chemotherapy: How the cardio-respiratory response to exercise is related to energy expenditure, fatigue, and adiposity in children with acute lymphoblastic leukaemia? European Journal of Cancer Care. https://doi.org/10.1111/ecc. 13418

Erdemir, E. (2020). Obezite Hastalarında Orta ve Yüksek Şiddette Uygulanan Aerobik Egzersizin Metabolik Faktörler, Vücut Kompozisyonu, Kas Gücü, Aerobik Kapasite Üzerine Olan Etkilerinin Karşılaştırılması. Yayımlanmamış Doktora Tezi, Süleyman Demirel Üniversitesi, Fiziksel T1p ve Rehabilitasyon Anabilim Dalı, Isparta.

Faulkner, J., O’Brien, W. J., McGrane, B., Wadsworth, D., Batten, J., Askew, C. D., Badenhorst, C., Byrd, E., Coulter, M., Draper, N., Elliot, C., Fryer, S., Hamlin, M. J., Jakeman, J., Mackintosh, K. A., McNarry, M. A., Mitchelmore, A., Murphy, J., Ryan-Stewart, H., ... Lambrick, D. (2020). Physical activity, mental health and well-being of adults during initial COVID-19 containment strategies: A multi-country cross-sectional analysis. Journal of Science and Medicine in Sport, November, 2020.07.15.20153791

Floyd, M. F., Nicholas, L., Lee, I., Lee, J.-H., ve Scott, D. (2006). Social Stratification in Recreational Fishing Participation: Research and Policy Implications. Leisure Sciences, 28(4), 351-368. https://doi.org/10.1080/014904006007458 $\underline{60}$

George, D. (2011). SPSS for windows step by step: A simple study guide and reference. Pearson Education India.

Grande, A. J., Keogh, J., Hoffmann, T. C., Beller, E. M., ve Del Mar, C. B. (2015). Exercise versus no exercise for the occurrence, severity and duration of acute respiratory 
infections. Cochrane Database of Systematic Reviews. https://doi.org/10.1002/14651858.CD0105 96.pub2

Gümüş, H., Alay Özgül, S., \& Karakiliç, M. (2017). Fiziksel Aktïvite İçin Park ve Rekreasyon Alanlarina Gelen Kullanicilarin Mekan Seçimini ve Fiziksel Aktiviteye Katilimini Etkileyen Faktörler. Spormetre, 15(1), 31-38.

Gümüş, H., Alay, Ö. S., ve Karakiliç, M. (2015). Fiziksel Aktivite Mekânı Değerlendirme Ölçeği (FAMDÖ): Geçerlik ve Güvenirlik Çalışması. Spor Bilimleri Dergisi, 26(1), $1-8$.

Gürbüz, S., ve Şahin, F. (2017). Sosyal Bilimlerde Araştırma Yöntemleri Felsefe-YöntemAnaliz (4. Baskı). Seçkin Yayıncılık.

Henderson, K. A. ve Dialeschki, M. D. (1991). A sense of entitlement to leisure as constraint and empowerment for women. Leisure Sciences, 13(1), 51-65. https://doi.org/10.1080/014904091095131 $\underline{24}$

Hudson, S. (2000). The Segmentation of Potential Tourists: Constraint Differences between Men and Women. Journal of Travel Research, 38(4), 363-368. https://doi.org/10.1177/004728750003800 404

Işıkgöz, E., Esentaş, M., ve Şahin, H. M. (2018). Beden Eğitimi ve Spor Alanında Öğrenim Gören Öğrencilerin Fiziksel Aktivite Mekân Seçimini ve Fiziksel Aktiviteye Katılımını Etkileyen Faktörlerin İncelenmesi. İnönü Üniversitesi Beden Ĕ̌itimi ve Spor Bilimleri Dergisi, 5(1), 21-32.

Jackson, E. L. ve Searle, M. S. (1985). Recreation Non-Participation And Barriers to Participation: Concepts, and Models. Loisir et Société / Society and Leisure, $8(2)$,

693-707. https://doi.org/10.1080/07053436.1985.10 715236

Jackson, E. L., Henderson, K. A., ve Henderson, K. A. (1995). Gender-based analysis of leisure constraints. Leisure Sciences, $17(1)$, 31-51. https://doi.org/10.1080/014904095095132 $\underline{41}$

Jackson, S. B., Stevenson, K. T., Larson, L. R., Peterson, M. N. ve Seekamp, E. (2021). Outdoor Activity Participation Improves Adolescents' Mental Health and WellBeing during the COVID-19 Pandemic. International Journal of Environmental
Research and Public Health, 18(5), 2506. https://doi.org/10.3390/ijerph18052506

Johnson, C. Y., Bowker, J. M., ve Cordell, H. K. (2001). Outdoor Recreation Coustraiuts: $\mathrm{Au}$ Examination of Race, Gender, and Rural Dwelling. Southern rural sociology, 17, 111-113.

Kavlak, H. T., Bayram, A. T., \& Çelen, O. (2020). K Kuşağııın Rekreasyona Katılımı ve Yaratıcı Düşünme Ĕ̆ilimi Arasındaki İlişki. B. Bayazıt, E. Karaçar \& O. Yılmaz, (Ed). Spor ve Rekreasyon Araştırmaları Kitabı-3 içinde (ss. 44-56). Ankara: Çizgi Kitabevi.

Kavlak, H. T., Düzgün, E., Karaçar, E., \& Zararsiz, H. F. (2021). Tiyatro Oyuncularının Boş Zaman Tatminleri ve Yaşam Doyumları Üzerine Bir Araştırma. Journal of Recreation and Tourism Research/JRTR, 8(1), 73-93.

Kelly, J. R. (1983). Leisure styles: A hidden core. Leisure sciences, 5(4), 321-338.

Kim, Y.-J., Cho, J.-H., \& Park, Y.-J. (2020). Leisure Sports Participants' Engagement in Preventive Health Behaviors and Their Experience of Constraints on Performing Leisure Activities During the COVID-19 Pandemic. Frontiers in Psychology, 11, 19.

Lee, J.-H., Scott, D., ve Floyd, M. F. (2001). Structural Inequalities in Outdoor Recreation Participation: A Multiple Hierarchy Stratification Perspective. Journal of Leisure Research, 33(4), 427449.

Morris, J. N., Heady, J. A., Raffle, P. A. B., Roberts, C. G., ve Parks, J. W. (1953). Coronary Heart-Disease and Physical Activity of Work. The Lancet, 262(6796), 1111-1120.

Nambi, G., Abdelbasset, W. K., Elshehawy, A. A., Eltrawy, H. H., Abodonya, A. M., Saleh, A. K., ve Hussein, R. S. (2021). Yoga in Burn: Role of pranayama breathing exercise on pulmonary function, respiratory muscle activity and exercise tolerance in full-thickness circumferential burns of the chest. Burns, 47(1), 206-214. https://doi.org/10.1016/j.burns.2020.06.03 3

Nathan, A., George, P., Ng, M., Wenden, E., Bai, P., Phiri, Z., ve Christian, H. (2021). Impact of COVID-19 Restrictions on Western Australian Children's Physical Activity and Screen Time. International Journal of Environmental Research and 
Aksu, H.S., Kaya, A., Arslan, F./Covid-19 Sürecinde Fiziksel Aktivite Amacıyla Açık Rekreasyon Alanlarını Tercih Eden Bireylerin Mekân Seçimi ve Fiziksel Aktiviteye Katılımını Etkileyen Faktörler

Public Health, 18(5), 2583. https://doi.org/10.3390/ijerph18052583

Nieman, D. C., ve Wentz, L. M. (2019). The compelling link between physical activity and the body's defense system. Journal of Sport and Health Science, 8(3), 201-217. https://doi.org/10.1016/j.jshs.2018.09.009

Onur, M. (2020). Covid-19 Salgın Döneminde Peyzaj ve İnsan İlişkisinin Mekânsal Tercihler Üzerinden İncelenmesi. Uluslararası Sosyal Araştırmalar Dergisi, 13(74), 1689-1699.

Paravidino, V. B., Mediano, M. F. F., Crochemore-Silva, I., da Cruz, V. L., Antunes, M. M. L., Beaulieu, K., Gibbons, C., Finlayson, G., Blundell, J. E., ve Sichieri, R. (2020). The compensatory effect of exercise on physical activity and energy intake in young men with overweight: The EFECT randomised controlled trial. Physiology \& Behavior, 113249.

Peçanha, T., Goessler, K. F., Roschel, H., ve Gualano, B. (2020). Social isolation during the COVID-19 pandemic can increase physical inactivity and the global burden of cardiovascular disease. American Journal of Physiology-Heart and Circulatory Physiology, 318(6), 1441-1446.

Pekel, H. A., Aydos, L., Uzun, A., Bozoğlu, M. S., \& Demirel, M. (2020). The Effect Of Zumba And Reformer Exercises On Female Body Composition. IJOEC, 5(11), 2316-2338.

Raymore, L. A., Godbey, G. C., ve Crawford, D. W. (1994). Self-Esteem, Gender, and Socioeconomic Status: Their Relation to Perceptions of Constraint on Leisure Among Adolescents. Journal of Leisure Research, 26(2), 99-118. https://doi.org/10.1080/00222216.1994.11 $\underline{969948}$

Scudiero, O., Lombardo, B., Brancaccio, M., Mennitti, C., Cesaro, A., Fimiani, F., Gentile, L., Moscarella, E., Amodio, F., Ranieri, A., Gragnano, F., Laneri, S., Mazzaccara, C., Di Micco, P., Caiazza, M., D’Alicandro, G., Limongelli, G., Calabrò, P., Pero, R., ve Frisso, G. (2021). Exercise, Immune System, Nutrition, Respiratory and Cardiovascular Diseases during COVID-19: A Complex Combination. International Journal of Environmental Research and Public Health, 18(3), 904. https://doi.org/10.3390/ijerph18030904
Shahidi, S. H., Stewart Williams, J., ve Hassani, F. (2020). Physical activity during COVID-19 quarantine. Acta Paediatrica, 109(10), 2147-2148. https://doi.org/10.1111/apa.15420

Shimada, T., Ito, S., Makabe, A., Yamanushi, A., Takenaka, A., ve Kobayashi, M. (2019). Aerobic exercise and cognitive functioning in schizophrenia: A pilot randomized controlled trial. Psychiatry Research, 282(1), 1-3. https://doi.org/10.1016/j.psychres.2019.11 $\underline{2638}$

Shores, K. A., Scott, D., ve Floyd, M. F. (2007). Constraints to outdoor recreation: A multiple hierarchy stratification perspective. Leisure Sciences, 29(3), 227246.

Stanis, S. A. W., Schneider, I. E., Chavez, D. J., ve Shinew, K. J. (2009). Visitor Constraints to Physical Activity in Park and Recreation Areas: Differences by Race and Ethnicity. Journal of park and recreation administration, 27(3), 78-95.

Stockwell, S., Trott, M., Tully, M., Shin, J., Barnett, Y., Butler, L., ... \& Smith, L. (2021). Changes in physical activity and sedentary behaviours from before to during the COVID-19 pandemic lockdown: a systematic review. BMJ Open Sport \& Exercise Medicine, 7(1), 1-8.

Tan, X., Alén, M., Wiklund, P., Partinen, M., ve Cheng, S. (2016). Effects of aerobic exercise on home-based sleep among overweight and obese men with chronic insomnia symptoms: a randomized controlled trial. Sleep Medicine, 25, 113121.

https://doi.org/10.1016/j.sleep.2016.02.01 $\underline{0}$

Taskin, M., Budak, H., Taskin, M., Bozoglu, M. S., \& Taskin, H. (2018). The effect of massage and kinesiotape applications on maximal squat strength. Ovidius University Annals, Series Physical Education and Sport/Science, Movement and Health, 18(2), 160-166.

Todd, S. L., Graefe, A. R., \& Mann, W. (2001). Differences in SCUBA diver motivations based on level of development. In Proceedings of the 2001 Northeastern Recreation Research Symposium. New York (pp. 107-114).

Toprakçı, E., ve Meşe, Ö. F. (2019). Türkiye'de Bireylerin Eğitim Düzeyi ile Sağlığı Arasındaki İlişkisi: Ulusal Veriler Işığında Bir Analiz. Mehmet Akif Ersoy Üniversitesi Eğitim Fakültesi Dergisi, 51, 
$118-143$.

https://doi.org/10.21764/maeuefd.552228

Torkildsen, G. (2005). Leisure and recreation management. London: Routledge.

Uzun, A., Akbulut, A., Erkek, A., Pamuk, Ö., \& Bozoğlu, M. S. (2020). Effect of age on speed and agility in early adolescence. International Journal of Applied Exercise Physiology, 9(8), 168-175.

Vancampfort, D., ve Ward, P. B. (2019). Physical activity correlates across the lifespan in people with epilepsy: a systematic review. Disability and Rehabilitation, 1-8. https://doi.org/10.1080/09638288.2019.16 $\underline{65113}$

Varol, F., Köseoğlu, A., ve Kuzu, Ö. H. (2019). Turizm Fakülteleri'nin Rekreasyon Eğitimi Üzerine Bir Araştırma. Uluslararası Tarih ve Sosyal Araştırmalar Dergisi, 21, 197-218.

WHO, (2020). Coronavirus disease (COVID-19): Staying active. Erişim adresi: https://www.who.int/news-room/q-adetail/coronavirus-disease-covid-19staying-active.

WHO, (2021). Stay physically active during selfquarantine. Erişim adresi: https://www.euro.who.int/en/healthtopics/health-emergencies/coronaviruscovid-19/publications-and-technicalguidance/noncommunicable-diseases/stayphysically-active-during-self-quarantine.

Woods, J. A., Hutchinson, N. T., Powers, S. K., Roberts, W. O., Gomez-Cabrera, M. C., Radak, Z., Berkes, I., Boros, A., Boldogh, I., Leeuwenburgh, C., Coelho-Júnior, H. J., Marzetti, E., Cheng, Y., Liu, J., Durstine, J. L., Sun, J., ve Ji, L. L. (2020). The COVID-19 pandemic and physical activity. Sports Medicine and Health Science, 2(2), 55-64. https://doi.org/10.1016/j.smhs.2020.05.00 $\underline{6}$

Zhang, X.-Y., Song, Y.-C., Liu, C.-B., Qin, C., Liu, S.-H., ve Li, J.-J. (2021). Effectiveness of oral motor respiratory exercise and vocal intonation therapy on respiratory function and vocal quality in patients with spinal cord injury: a randomized controlled trial. Neural Regeneration Research, 16(2), 375. https://doi.org/10.4103/1673-5374.290909 